\title{
Improving severe pediatric asthma outcomes with the implementation of a multidisciplinary program
}

\author{
Alvaro Teijeiro ${ }^{1}$, Ruben Vieyra ${ }^{1}$, Analia Arteaga ${ }^{2}$, Maximiliano Ermoli ${ }^{3}$, Carolina Bustos ${ }^{4}$, \\ Susana Saenz ${ }^{1}$, and Anahí Yañez \\ ${ }^{1}$ Pediatric Hospital of Cordoba \\ ${ }^{2}$ Pediatric Hospital of Cordoba \\ ${ }^{3}$ Pediatric Hospital of Cordoba, Argentina \\ ${ }^{4}$ Pedaitric Hospital of Cordoba \\ ${ }^{5}$ Investigaciones en Alergia y Enfermedades Respiratorias- InAER
}

June 23, 2021

\begin{abstract}
Introduction: The implementation of interdisciplinary care strategies for the follow-up of patients with asthma has proven to be very effective in improving the long-term evolution of these children. Objectives: Describe the clinical, functional and therapeutic characteristics of patients with a diagnosis of uncontrolled severe asthma (UCSA), identify the differences in the characteristics in the management between patients with difficult-to-treat severe asthma (SDCA) and treatment-resistant severe asthma (STRA Materials: Analytical study of serial cases, patients were evaluated for 6 months, patients with UCSA diagnosis were admitted to the Pneumonology Service of the Pediatric Hospital of Córdoba, with ages between 5 and 15 years old. Results: 23 patients entered the study. $47.82 \%$ were defined as SDCA and 52.17\% STRA. During the first 6 months of the program; hospitalizations were only $4 \%$ (p: 0.001). Besides, the number of visits to the emergency room decreased to $39.13 \%$ (p: 0.003). Regarding the Inhalation technique, $73.9 \%$ (n: 17) presented improvement (p: 0.0001$)$. Only $13 \%$ ( $\mathrm{n}=3$ ) of the patients continued with ACT $<20$ (p: 0.0001). We found differences in the use of rescue medication (p: 0.003) and greater attendance at Emergency Rooms (p: 0.005), during the 6-month evaluation process, in favor of the group of treatment-resistant asthmatics Conclusion: Implementing this type of interdisciplinary program allowed a marked improvement in all modifiable variables of asthma in patients with SDCA. All this not only leads to improving the management of patients with UCSA.
\end{abstract}

Title Page:

Improving severe pediatric asthma outcomes with the implementation of a multidisciplinary program Authors

Alvaro Teijeiro M.D. Ph.D.; Pediatric Hospital of Cordoba, Respiratory Center

Ruben Vieyra MD.; Pediatric Hospital of Cordoba, Respiratory Center

Analia Arteaga Psych.; Pediatric Hospital of Cordoba, Mental Health

Maximiliano Ermoli Psych.; Pediatric Hospital of Cordoba, Argentina, Mental Health

Carolina Bustos Klgo. MSc. Pediatric Hospital of Cordoba, Pulmonary Physiotherapy

Susana Graciela Saenz Klgo.; Pediatric Hospital of Cordoba, Pulmonary Physiotherapy

Anahí Yañez M.D.; Investigaciones en Alergia y Enfermedades Respiratorias InAER, Research in Allergy and Respiratory Diseases 
Corresponding Author : Castro Barros 650, X5000, Cordoba, Argentina. email:ateijeirom@gmail.com

Any disclosures and funding information statements:Astra Zeneca- Editorial support, under the direction of the author

Keys Words : Pediatric Asthma, Severe Asthma Program, uncontrolled severe asthma

Abbreviated (running) title: Pediatric Severe Asthma Program

\section{Hosted file}

Main Document.docx available at https://authorea.com/users/421246/articles/527354-improvingsevere-pediatric-asthma-outcomes-with-the-implementation-of-a-multidisciplinary-program

\section{Hosted file}

Table 1. docx available at https://authorea.com/users/421246/articles/527354-improving-severepediatric-asthma-outcomes-with-the-implementation-of-a-multidisciplinary-program

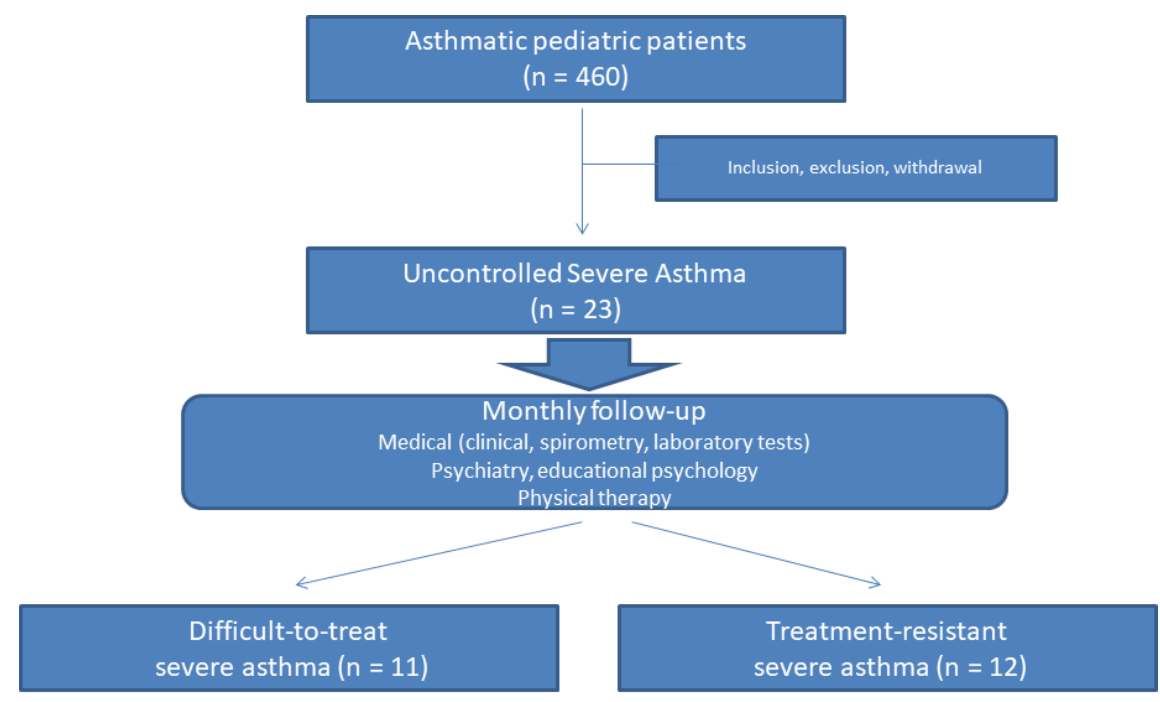

Figure 1. Patient disposition 


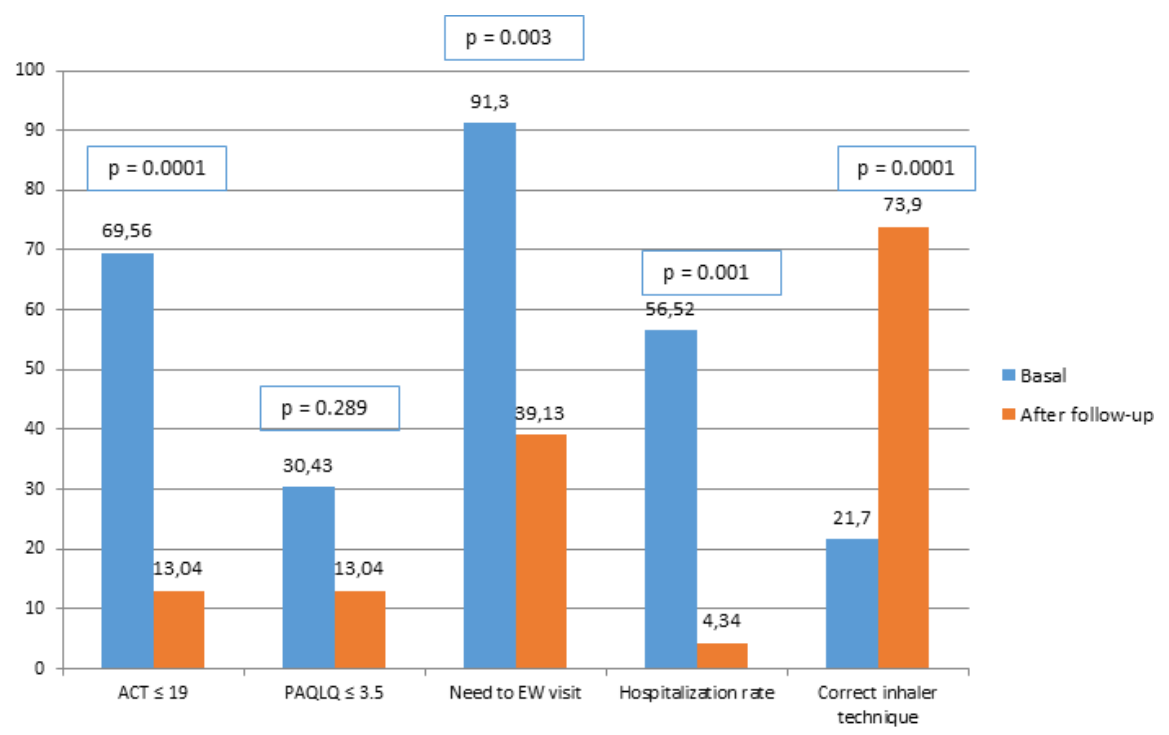

Figure 2. Impact of program implementation

ACT: Asthma Control Test; EW: emergency ward; PAQLQ: Pediatric Asthma Quality of Life Questionnaire

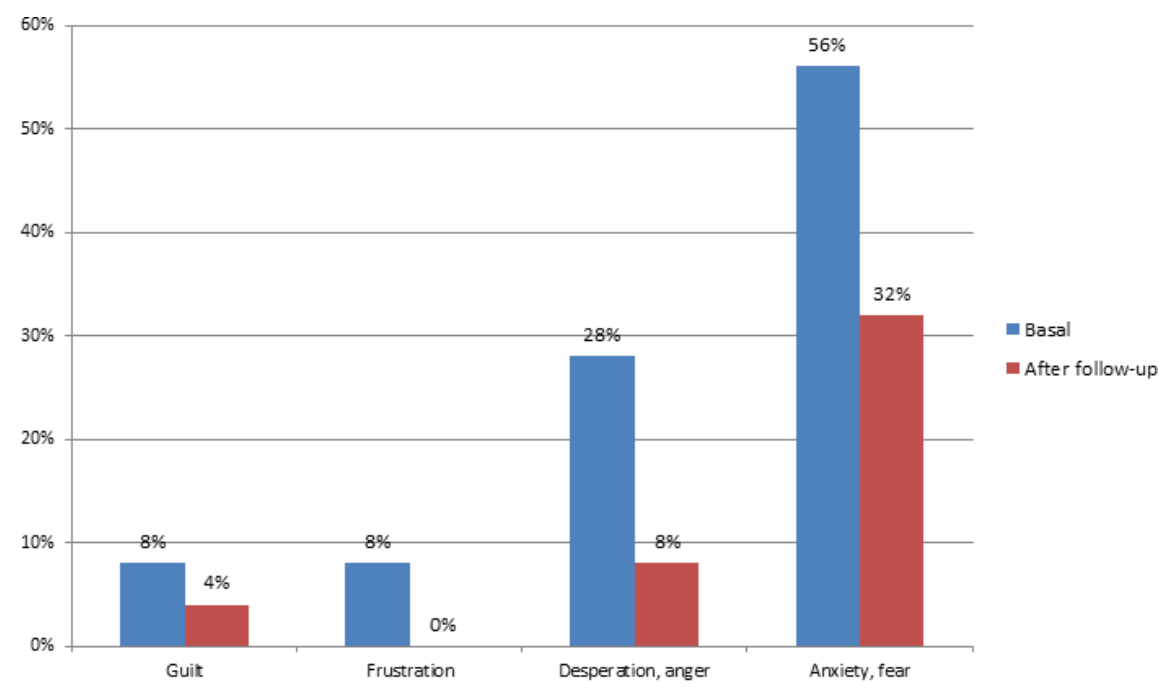

Figure 3. Caregivers' reactions during asthma exacerbations ACT: Asthma Control Test; EW: emergency ward; PAQLQ: Pediatric Asthma Quality of Life Questionnaire

Hosted file 
Table 2.docx available at https://authorea.com/users/421246/articles/527354-improving-severepediatric-asthma-outcomes-with-the-implementation-of-a-multidisciplinary-program 